\section{$16^{\circ}$ \\ ERGODESIGN USIHC CINAHPA}

$16^{\circ}$ Ergodesign - Congresso Internacional de Ergonomia e Usabilidade de Interfaces Humano Tecnológica: Produto, Informações Ambientes Construídos e Transporte

$16^{\circ}$ USIHC - Congresso Internacional de Ergonomia e Usabilidade de Interfaces Humano Computador

CINAHPA | 2017 - Congresso Internacional de Ambientes Hipermídia para Aprendizagem.

\title{
NAVEGAÇÃO DE SURDOS EM WEBSITES A PARTIR DE ÍCONES GRÁFICOS
}

\author{
DEAF NAVIGATION IN WEBSITES \\ FROM GRAPHIC ICONES
}

\author{
Carla da Silva Flor ${ }^{1}$, Dra. \\ Tarcísio Vanzin², Dr. \\ (1) Universidade Federal de Santa Catarina \\ e-mail: carla.flor@gmail.com \\ (2 Universidade Federal de Santa Catarina \\ e-mail: tvanzin@gmail.com
}

Palavras-chave: Ícones gráficos, avaliação de usabilidade, surdos.

Este artigo relata as etapas de uma pesquisa cujo objetivo foi estudar formas de representação de ícones gráficos para facilitar a navegação de surdos pré-linguísticos em websites. Devido à dificuldade desse público com as informações escritas e a percepção visual aguçada, viu-se a possibilidade de se utilizar os ícones gráficos como mediadores da navegação. Após a revisão de alguns conceitos semióticos, elaborou-se quatro pressupostos que serviram de base para a criação de uma interface digital que foi utilizada em uma avaliação de usabilidade a partir de testes com dez usuários surdos. Ao final do experimento, três dos quatro pressupostos puderam ser confirmados, enquanto um deles suscitou dúvida nos participantes. Espera-se que a partir dos resultados obtidos, a concepção de ícones gráficos possa ser realizada no intuito de tornar os sites mais acessíveis ao surdo pré-linguístico.

\section{Graphic icon, usability evaluation, deaf.}

This article reports the stages of a research which aim was to study the forms of representing graphic icon to facilitate the navigation of pre-linguistic deaf in websites. Due to this public difficulty with written information and the visual perception sharpened, it was verified the possibility of using graphic icons as navigation mediators. After the review of some semiotic concepts, four assumptions, which worked as base for the creation of a digital interface was created and was used in a usability evaluation from tests with ten deaf users. At the end of the experiment, three of the four assumptions could be confirmed meanwhile one of them brought doubts on the participants. It is expected that from the results obtained, the conception of graphic icons can take place with the objective of making the sites more accessible to pre-linguistic deaf. 


\section{$16^{\circ}$ \\ ERGODESIGN USIHC CINAHPA}

\section{Introdução}

Websites são compostos tanto por informações gráficas quanto textuais. Ocorre que a maioria desses websites supervaloriza a informação textual utilizando a informação gráfica apenas como um apoio. Existe, no entanto, um grupo de usuários que tem dificuldades com a informação textual e no qual a informação gráfica é mais atrativa e acessível. Esse grupo de usuários é composto por pessoas que nasceram surdas ou que deixaram de ouvir muito cedo, antes de adquirirem a língua oral. Para eles, a dificuldade de relacionar os fonemas com símbolos escritos reflete na aprendizagem da modalidade escrita da língua, o que gera consequências graves na sua alfabetização. Normalmente os surdos prélinguísticos, como são chamados, apresentam dificuldades em conjugar verbos, em utilizar pronomes demonstrativos, possessivos e pessoais, em utilizar preposições, dentre outros problemas que incidem na sua capacidade de produção e compreensão textual (QUEVEDO, 2013).

Em paralelo à dificuldade com a língua oral, os surdos aparentam ter uma capacidade de percepção visual bastante desenvolvida. Como muitas crianças surdas chegam à escola sem saber a língua de sinais, que é a língua apropriada para esse público, a imagem acaba sendo um recurso bastante explorado na sala de aula e acaba tendo um importante papel para os surdos ao longo de suas vidas. Apesar de muitos conceitos não serem tão fáceis de serem ilustrados com facilidade, as imagens apresentam a vantagem sobre os vídeos em língua de sinais por poderem ser decodificadas rapidamente, enquanto os vídeos podem se tornar demorados e cansativos (REITSMA, 2008).

Embora a utilização de ícones gráficos em websites pareça suscitar essa percepção visual dos surdos, facilitando a sua navegação e, consequentemente, melhorando o seu desempenho na busca por informações disponíveis on-line, na prática os ícones também podem ser difíceis de serem compreendidos se não bem representados. Isso ocorre porque as imagens também podem ser polissêmicas, ou seja, podem representar vários $16^{\circ}$ Ergodesign - Congresso Internacional de Ergonomia e Usabilidade de Interfaces Humano Tecnológica: Produto, Informações Ambientes Construídos e Transporte

$16^{\circ}$ USIHC - Congresso Internacional de Ergonomia e Usabilidade de Interfaces Humano Computador

CINAHPA | 2017 - Congresso Internacional de Ambientes Hipermídia para Aprendizagem.

conceitos ao invés de apenas um. Por conta disso, os ícones precisam ser pensados e criados dentro de contextos que possam ser interpretados pelos surdos (SANTAELLA; NÖTH, 2009).

Com base nestas informações, este artigo se propõe a estudar formas de representação de ícones gráficos para facilitar a navegação de surdos em websites. Baseando-se em alguns pressupostos iniciais sobre a linguagem gráfica dos ícones, uma interface digital foi desenvolvida para a avaliação de usabilidade a partir da aplicação de testes empíricos com usuários surdos. Os principais conceitos que sustentam a pesquisa, bem como o planejamento, a aplicação e os resultados dos testes podem ser vistos a seguir.

\section{Linguagem gráfica utilizada em websites}

Como foi visto, os websites utilizam tanto a linguagem verbal como a gráfica para se comunicar com o seu público-alvo. A linguagem gráfica é um campo que vem sendo estudado por muitos anos por especialistas em semiótica, que buscam classificá-la como signos visuais. Dentre as classificações mais respeitadas e mundialmente reconhecidas está a teoria de Peirce (2005), que dividiu os signos em ícones, índices e símbolos.

Para o autor, um ícone é um signo que representa o objeto principalmente por meio da similaridade. A qualidade desse signo, tal como a forma, a cor, a textura, o som, o cheiro, etc., podem substituir o objeto, uma vez que compartilham a semelhança. No entanto, essas qualidades também podem substituir outros objetos que compartilhem a mesma qualidade. Para exemplificar, um círculo pode representar um sol, uma lua ou uma bola, pois em todos os casos a forma é circular (PERASSI, [2009?]). Quando existe essa relação de similaridade e comparação, o signo é chamado de hipoícone. Esse hipoícone pode ser uma imagem propriamente dita, um diagrama, ou uma metáfora. As imagens propriamente ditas são signos que compartilham com o objeto alto nível de semelhança e qualidade, o que Peirce chama de Primeiras Primeiridades, ou seja, "similaridade na aparência" (SANTAELLA; NÖTH, 2009, p. 62). Segundo Peirce (2005, p. 64), "qualquer imagem 


\section{$16^{\circ}$ \\ ERGODESIGN USIHC CINAHPA}

material, como uma pintura, por exemplo, é amplamente convencional em seu modo de representação; contudo, em si mesma, sem legenda ou rótulo, pode ser denominada de hipoícone". Já o segundo tipo de hipoícone, ou seja, os diagramas, não compartilham necessariamente a semelhança e a qualidade com o objeto, mas sim as relações análogas. Por último, as metáforas compartilham a semelhança de significado entre o objeto e algo diverso. Assim, "uma imagem possui uma similaridade na aparência, o diagrama, nas relações, e a metáfora, no significado" (SANTAELLA; NÖTH, 2009, p. 62).

Diferentemente do ícone, o índice não possui qualquer relação com o objeto, senão uma relação factual que surge na interpretação (PERASSI, [2009?]). Por exemplo, um barômetro que marca pressão baixa e alta unidade no ar indica chuva, pois "as formas da natureza estabelecem uma conexão provável entre o barômetro que marca pressão baixa com o ar úmido e a chuva iminente" (PEIRCE, 2005, p.67). Na aplicação web, índices são encontrados sobretudo em fotografias, que possuem uma relação causal com a realidade em função das leis da ótica. Elas possuem uma ligação física com o objeto, correspondendo à natureza. No entanto, as fotografias também são ícones em função das semelhanças entre as suas qualidades e as dos objetos (SANTAELLA; NÖTH, 2009). Outros exemplos aplicados à web são os desenhos de setas que são índices de direção.

O símbolo, por sua vez, não compartilha a semelhança com o objeto tal qual o ícone, nem tampouco possui uma conexão causal, factual, física ou concreta, como o índice, mas participa de uma relação com o objeto de acordo com processo de mediação, no qual o significado é atribuído por um hábito ou convenção. A palavra é um símbolo que denota um objeto a partir de uma lei, uma convenção estabelecida, e por isso, pode se tornar abstrata e generalizável. No entanto, para se materializar, o símbolo necessita de casos individuais, podendo agregar dentro dele ícones e índices (SANTAELLA; NÖTH, 2009). De acordo com Peirce (2005, p. 71) "uma lei necessariamente governa ou 'está corporificada em' individuais, e prescreve algumas de suas qualidades. $16^{\circ}$ Ergodesign - Congresso Internacional de Ergonomia e Usabilidade de Interfaces Humano Tecnológica: Produto, Informações Ambientes Construídos e Transporte

$16^{\circ}$ USIHC - Congresso Internacional de Ergonomia e Usabilidade de Interfaces Humano Computador

CINAHPA | 2017 - Congresso Internacional de Ambientes Hipermídia para Aprendizagem.
Consequentemente, um constituinte de um Símbolo, pode ser um Índice, e um outro constituinte pode ser um Ícone".

Na aplicação à web, é comum utilizar-se o termo ícone para as imagens estilizadas que são utilizadas na navegação. Isso se deve, sobretudo, porque as qualidades do signo se assemelham às qualidades do objeto. No entanto, muitas dessas imagens já são familiares aos usuários, o que faz com que o hábito ou convenção sejam mais fortes para o reconhecimento do objeto do que suas qualidades. É o que ocorre com a ilustração de uma carta (Figura 1), cuja qualidade (forma) se assemelha à qualidade de um objeto real (hipoícone), para representar outra coisa (e-mail) que tem a mesma finalidade de enviar mensagens (metáfora) e que também, por meio do hábito de uso, vem sendo utilizada para simbolizar qualquer tipo de contato (e-mail, telefônico) genericamente (símbolo).

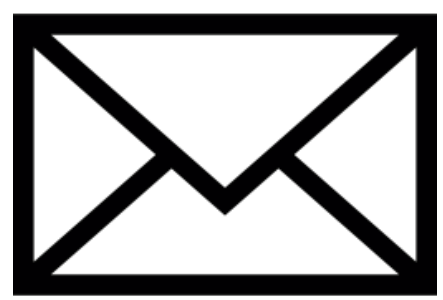

Figura 1 - Ilustração de uma carta, que pode atuar como hipoícone, metáfora e símbolo. Fonte: Freepik (2015).

A utilização da linguagem gráfica para a navegação em websites, no entanto, têm sido alvo de constantes estudos, devido ao caráter polissêmico da imagem. De acordo com Fajardo, Abascal e Cañas (2004) devido às diferentes formas de organizar o conhecimento na memória, pode haver uma distância semântica no julgamento da relação ícone-referente, que poderá afetar a decisão na seleção de um hiperlink gráfico. Isso porque nem todos os usuários poderão ter o mesmo entendimento ao extrair o significado desta imagem, sobretudo, em função de como essas imagens estão organizadas na estrutura do site, já que quando imagens similares estão muito próximas pode ocorrer ambiguidade. Uma maneira proposta por Hicks (2011) para diferenciar essas imagens é utilizar a combinação de elementos para ícones com funções similares, como, por exemplo, adicionar o sinal de mais (+) ou de menos (-) para
Realização:

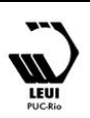




\section{$16^{\circ}$ \\ ERGODESIGN USIHC CINAHPA}

o ícone de documentos, para representar adicionar documento ou remover documento.

\section{Planejamento}

Como visto anteriormente, as imagens têm sido utilizadas há tempos na educação de surdos e também têm sido utilizadas na comunicação dos websites na forma de ícones gráficos. O problema relacionado aos ícones é que se não bem planejados podem gerar ambiguidades por conta do seu caráter polissêmico. Assim, a pesquisa descrita neste artigo se propõe a estudar formas de representação de ícones gráficos que facilitem a navegação de surdos em websites. Para isso, elaborou-se quatro pressupostos relacionados à criação de ícones baseando-se nos conceitos apresentados no tópico anterior, tais como:

a) Ícones icônicos: Ícones que compartilham a semelhança na forma com o objeto que representam podem ser imediatamente reconhecidos pelos usuários mesmo que eles nunca os tenham visto (possuem a qualidade de Primeiridade descrita por Peirce (2005) em relação à forma). Esse pressuposto se aplica igualmente aos usuários surdos.

b) Ícones convencionalizados: Ícones que são reconhecidos de maneira imediata por um público muito amplo nem sempre são fáceis de encontrar (NIELSEN, 2014), porém alguns ícones já convencionalizados pelo uso tornaram-se familiares e funcionais (HICKS, 2011). Nestes casos, o mais apropriado seria utilizar a convenção, mesmo em casos de metáforas que não são compartilhadas entre surdos e ouvintes, uma vez que os surdos são, como já foi dito anteriormente, usuários que se baseiam especialmente na visão, e portanto, podem ter memorizado os ícones em experiências de navegação anteriores.

c) Categorias abstratas: Categorias abstratas são altamente polissêmicas, pois utilizar uma imagem para representá-la pode permitir confundi-la com uma $16^{\circ}$ Ergodesign - Congresso Internacional de Ergonomia e Usabilidade de Interfaces Humano Tecnológica: Produto, Informações Ambientes Construídos e Transporte

$16^{\circ}$ USIHC - Congresso Internacional de Ergonomia e Usabilidade de Interfaces Humano Computador

CINAHPA | 2017 - Congresso Internacional de Ambientes Hipermídia para Aprendizagem. subcategoria. Propõe-se duas formas de solucionar o problema: 1) utilizar apenas características que os subitens possuem em comum; 2) agrupar ou mesclar características de mais de uma subcategoria no mesmo ícone.

d) Ícones polissêmicos ou que englobam mais de um conceito: Alguns hiperlinks podem aparecer mais de uma vez na interface, porém associados a categorias diferentes e com significados diferentes. Nestes casos, o melhor seria combinar o ícone com elementos que identifiquem a sua categoria imediata, conforme a combinação de elementos proposta por Hicks (2011).

Com base nestes pressupostos, o passo seguinte foi a elaboração da interface digital para a utilização nos testes empíricos com usuários surdos, a fim de avaliar a navegabilidade dos ícones criados.

\subsection{Design e geração de alternativas}

Para a elaboração da interface digital, o primeiro passo adotado foi uma pesquisa a respeito das tendências estilísticas para websites utilizadas. Percebeu-se uma forte utilização do Flat design, que é um estilo gráfico marcado pela simplicidade das formas, sobretudo pela utilização de formas planas, como retângulos, quadrados e círculos, e uso de cores saturadas e vibrantes, sem efeitos de degradê (SÁ, 2014). Portanto, optou-se por utilizar o menu em forma de retângulos ou quadrados, a depender da resolução da tela, já que o flat design segue também a tendência do layout responsivo, que "visa a adaptação dos mesmos conteúdos a diferentes dispositivos digitais" (SÁ, 2014, p.81).

Após alguns estudos, chegou-se à alternativa escolhida, que diferenciava as seções do menu por cores e ícones. No primeiro nível do menu, os ícones foram posicionados logo acima do texto, enquanto no segundo e no terceiro nível foram colocados no canto esquerdo do texto. Algumas páginas de conteúdo também possuíam ícones, como pode-se ver na Figura 2. Para a elaboração do design dos ícones utilizou-se o mesmo estilo gráfico já adotado para o site (Flat design). 


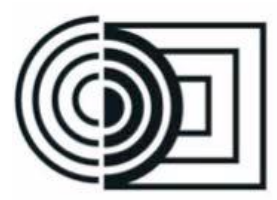

$16^{\circ}$ Ergodesign - Congresso Internacional de Ergonomia e Usabilidade de Interfaces Humano Tecnológica: Produto, Informações Ambientes Construídos e Transporte

$16^{\circ}$ USIHC - Congresso Internacional de Ergonomia e Usabilidade de Interfaces Humano Computador

CINAHPA | 2017 - Congresso Internacional de Ambientes Hipermídia para Aprendizagem.

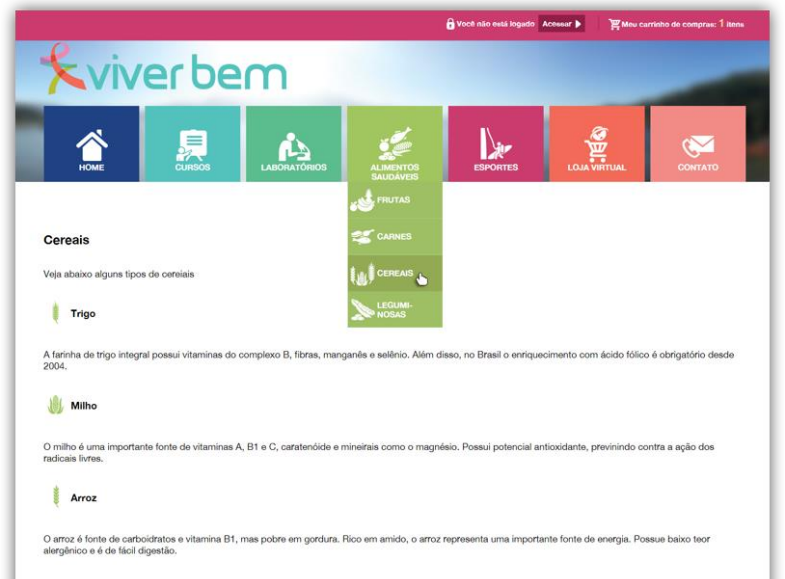

9

Figura 2 - Interface digital da versão com Ícones. Fonte: Flor (2016).

\subsection{Elaboração dos ícones com base nos pressupostos}

Para a elaboração dos ícones dispostos no website de teste, adotou-se como metodologia, primeiramente, a pesquisa dos ícones que já estavam convencionalizados, a fim de atender o pressuposto $b$ (utilizar a convenção, mesmo em casos de metáforas). Para auxiliar na análise foram consultados os repositórios de ícones sugeridos por Hicks (2011): The Noun Project (http:// thenounproject.com), Iconfinder (https://www. iconfinder.com/), e Google Imagens (https:// images.google.com/); além da plataforma Flaticon (http://www.flaticon.com/), que disponibiliza ícones para donwload gratuito. Digitou-se o termo no campo de busca e analisou-se os resultados. Se as imagens resultantes fossem unânimes, ou seja, retornassem a representação do mesmo objeto, considerou-se que o ícone já era convencionalizado. Caso o resultado fosse imagens aleatórias, considerou-se que o ícone não era convencionalizado. Para exemplificar, pesquisouse o termo "cart" (tradução de carrinho) nos quatro sites e como se obteve quase que exclusivamente a representação de um carrinho de compras, considerou-se o ícone como convencionalizado. A partir desse método, os ícones que já possuíam uma convenção foram desenhados com base na simbologia já preestabelecida.
Para os demais ícones seguiu-se os pressupostos $a$, $c$ e $d$. Por exemplo, para os ícones relacionados a apenas uma fruta utilizou-se o pressuposto $a$ (ícone icônico), com o desenho de um abacate, um abacaxi, uma banana, etc. Já para o ícone relacionados à categoria frutas, utilizou-se o pressuposto $c$ (categorias abstratas), com a reunião das representações de três frutas (laranja, banana e abacaxi) e para o ícone de loja virtual, ao pesquisar a convenção preestabelecida nos repositórios de ícones, encontrou-se o mesmo ícone de carrinho de compras, portanto, utilizou-se o pressuposto $d$ (ícones polissêmicos), adicionando ao carrinho o símbolo de um globo terrestre, que está associado à ideia de internet, esperando que o usuário fizesse a associação de "carrinho = compras" + "globo = virtual". Alguns exemplos dos ícones podem ser visualizados na Figura 3.

Após a definição da interface digital e dos ícones, a próxima etapa foi a elaboração das tarefas que seriam solicitadas aos participantes.
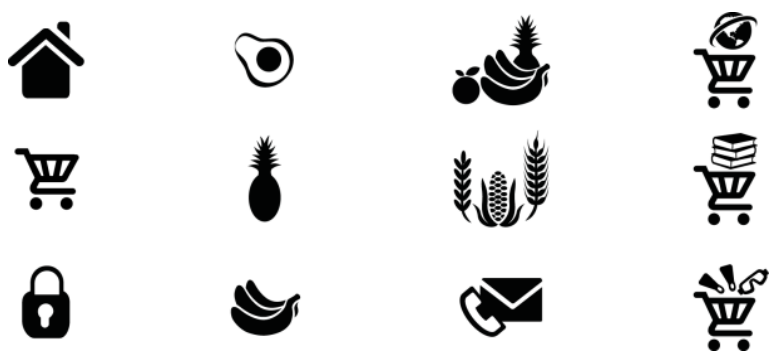

Figura 3 - Exemplos de ícones elaborados para a interface de teste. Fonte: Flor (2016).

\subsection{Tarefas}

Para que os usuários pudessem buscar determinadas informações no site e, com isso, testar a navegabilidade dos ícones, criou-se uma lista de tarefas. Essas tarefas consistiam, basicamente, na pergunta sobre alguma informação que estava disponível no site e que eles deveriam buscar, copiar e colar em um campo de formulário. Também haviam tarefas com ações que eles deveriam exercer diretamente no site, como adicionar algo ao carrinho de compras ou enviar um e-mail no campo de contato.
Realização:
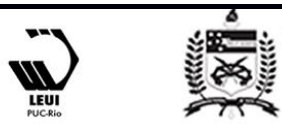


\section{$16^{\circ}$ \\ ERGODESIGN USIHC CINAHPA}

Para que a verificação do desempenho dos ícones fosse ainda mais satisfatória, elaborou-se tarefas que propositalmente poderiam levar o usuário ao erro caso o ícone não fosse bom o suficiente. Por exemplo, adicionou-se palavras ambíguas próximas ou com forma ortográfica semelhante às do ícone que ele deveria clicar para encontrar a informação requerida. A lista completa das tarefas pode ser vista no Quadro 1.

A fim de facilitar o entendimento da questão, todas as perguntas foram traduzidas para a língua de sinais, de forma que na página constavam, nesta ordem, o vídeo da questão na Língua Brasileira de Sinais (Libras), a pergunta em português e o respectivo campo do formulário para ser preenchido.

\begin{tabular}{|l|}
\hline Tarefas \\
\hline 1) Pesquise quais são as propriedades nutricionais da laranja \\
\hline $\begin{array}{l}\text { 2) Qual é a aula ministrada na sexta-feira no curso de } \\
\text { gastronomia? }\end{array}$ \\
\hline 3) Qual a capacidade máxima de pessoas em cada laboratório? \\
\hline 4) Quais os cursos disponíveis na área de saúde? \\
\hline $\begin{array}{l}\text { 5) Qual é o endereço de e-mail para você falar com o responsável } \\
\text { pelo site? }\end{array}$ \\
\hline $\begin{array}{l}\text { 6) Envie uma mensagem para o responsável pelo formulário } \\
\text { eletrônico }\end{array}$ \\
\hline 7) Qual é a mensagem que aparece ao fazer login na sua conta? \\
\hline 8) O que é necessário para se tornar competidor esportivo? \\
\hline 9) Quem escreveu o livro Saúde de A a Z? \\
\hline $\begin{array}{l}\text { 10) Clique em adicionar ao carrinho para comprar futuramente o } \\
\text { livro Saúde de A a Z? }\end{array}$ \\
\hline $\begin{array}{l}\text { 11) Qual é o projeto de pesquisa responsável por promover a } \\
\text { acessibilidade do site? }\end{array}$ \\
\hline 12) Quais artigos esportivos masculinos estão à venda? \\
\hline
\end{tabular}

$16^{\circ}$ Ergodesign - Congresso Internacional de Ergonomia e Usabilidade de Interfaces Humano Tecnológica: Produto, Informações Ambientes Construídos e Transporte

$16^{\circ}$ USIHC - Congresso Internacional de Ergonomia e Usabilidade de Interfaces Humano Computador

CINAHPA | 2017 - Congresso Internacional de Ambientes Hipermídia para Aprendizagem.

\begin{tabular}{l}
$\begin{array}{l}\text { 13) Clique em adicionar ao carrinho para comprar futuramente a } \\
\text { prancha de surfe }\end{array}$ \\
\hline 14) Quais minerais têm a fruta manga? \\
\hline 15) Qual é o valor total do seu carrinho de compras? \\
\hline $\begin{array}{l}\text { 16) Sobre o que é a palestra anunciada no banner na página } \\
\text { inicial do site? }\end{array}$ \\
\hline 17) Baixe uma foto a respeito de surfe na galeria de fotos
\end{tabular}

Quadro 1 - Tarefas propostas aos participantes surdos. Fonte: Flor (2016).

\section{Método}

Após o planejamento e a implementação do protótipo de website, sucedeu-se à aplicação dos testes empíricos com usuários. Para isso, primeiramente foi realizada a seleção dos participantes surdos e, em seguida, a condução dos testes propriamente dita.

\subsection{Perfil dos participantes selecionados}

Participaram da pesquisa 10 usuários da Libras, de idade entre 20 e 38 anos, que ficaram surdos até os quatro anos de idade, prevalecendo os surdos congênitos ( $70 \%$ dos participantes). No que se refere à escolaridade, nove cursavam o ensino superior e um já havia terminado a graduação, apesar de $40 \%$ terem afirmado sentir dificuldades no dia a dia com o português: "dependendo do texto ou do gênero textual eu posso ter mais dificuldade. Alguns significados para mim ficam claros, outros não"; $40 \%$ terem considerado que leem e escrevem bem, mesmo com dificuldades em determinados termos ou palavras: "eu entendo bem as palavras, mas tem uma palavra em português que surge no meio da frase e isso prejudica o meu entendimento"; e apenas $20 \%$ terem relatado compreender bem o português.

Em relação à experiência com websites, todos os participantes já haviam navegado em websites anteriormente. A maioria dos usuários relatou navegar com frequência em websites.

\subsection{Condução dos testes empíricos com usuários}

Realização:

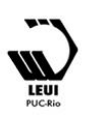




\section{$16^{\circ}$ \\ ERGODESIGN USIHC CINAHPA}

Os testes empíricos foram realizados entre fevereiro e abril de 2016, com o auxílio de intérprete de Libras. Antes de iniciar o teste, os participantes foram informados sobre os riscos e benefícios de sua participação na pesquisa e assinaram um Termo de Consentimento Livre e Esclarecido (TCLE), elaborado com base na Resolução CNS 466/12, de 12/09/2012. Depois da assinatura, os participantes receberam orientações sobre o objetivo do teste e lhes foram apresentados tanto a página que continha as tarefas quanto a versão do site onde deveriam buscar as informações. $\mathrm{O}$ registro das atividades foi realizado com o auxílio de câmeras de vídeo, software gravador de tela e pelo envio do formulário de tarefas.

\section{Resultados}

O material utilizado para a avaliação de usabilidade foi composto das gravações das telas e das câmeras e dos formulários enviados pelos participantes. Foram descartadas as respostas dos participantes que não compreenderam a pergunta, preenchendo-as com informações pessoais ou aleatórias, ou daqueles que não tentaram respondêlas. Portanto, foram consideradas válidas as respostas dos participantes que responderam com informações contidas no site ou que realizaram a busca mas não preencheram o formulário em virtude de não conseguirem encontrar a resposta. $\mathrm{O}$ resultado das avaliações, de acordo com os pressupostos a respeitos dos tipos de ícones, as tarefas realizadas e a média de acertos, pode ser visto no Quadro 2.

\begin{tabular}{|l|l|l|}
\hline Pressupostos & Tarefas associadas & $\begin{array}{l}\text { Média de } \\
\text { acertos* }\end{array}$ \\
\hline Ícone Icônico & $1,3,8,14,17$ & $81,54 \%$ \\
\hline Ícone Convencionalizado & $2,7,16,10,13,15$ & $91,28 \%$ \\
\hline Ícone Categorias abstratas & $4,5,6,11,12$ & $96,00 \%$ \\
\hline Ícone Polissêmicos & $9,10,13,15$ & $91,92 \%$ \\
\hline * Considerando somente as respostas válidas. \\
\hline
\end{tabular}

Quadro 2 - Pressupostos e média de acertos das tarefas realizadas pelos participantes surdos. Fonte: Elaborado pelos autores. $16^{\circ}$ Ergodesign - Congresso Internacional de Ergonomia e Usabilidade de Interfaces Humano Tecnológica: Produto, Informações Ambientes Construídos e Transporte

$16^{\circ}$ USIHC - Congresso Internacional de Ergonomia e Usabilidade de Interfaces Humano Computador

CINAHPA | 2017 - Congresso Internacional de Ambientes Hipermídia para Aprendizagem.

Como pode-se perceber no Quadro 2, o pressuposto $a$ obteve uma média de $81,54 \%$ de acertos das respostas consideradas válidas. Esse valor só não foi maior porque na questão 8 os participantes precisavam navegar no site até uma determinada página, denominada esportes, onde estava posicionado o ícone que deveriam clicar, porém alguns participantes não conseguiram chegar na página esportes. Ainda assim, o valor elevado do índice de acertos dos participantes em relação às tarefas que necessitavam do clique em ícones icônicos faz entender que eles são representativos do objeto e facilmente reconhecíveis, confirmando os conceitos de Primeiridade estabelecidos por Peirce (2005).

Em relação aos ícones convencionalizados, também se confirmou o pressuposto $b$, que diz que ícones que já são conhecidos pelos usuários são facilmente reconhecidos, mesmo que eles não tenham uma relação direta com o objeto, a não ser pela convenção estabelecida. Esse resultado pôde ser confirmado, sobretudo, pela tarefa 16, que necessitava do clique no ícone de uma casa como representativa da palavra em inglês home, que em português é traduzida como página inicial. Para o surdo que já tem dificuldades com o português, compreender que o símbolo de uma casa é a representação de home, em inglês, é ainda mais complexo, no entanto, como os participantes já estavam acostumados a navegar na internet, $\mathrm{o}$ símbolo da casa soou familiar para eles, que já os haviam utilizado em outros sites.

As tarefas relacionadas com o pressuposto $c$ que tratava das categorias abstratas foi o que teve o maior índice de acertos, confirmando-o. Ficou evidente na tarefa 4 que os ícones das diversas categorias se ajudavam mutuamente para que a escolha do participante fosse a correta, uma vez que $40 \%$ dos participantes chegaram a passar o mouse sobre o item alimentos saudáveis, mas quando percebiam que os ícones dessa categoria estavam relacionados a comida e não a cursos, desistiam, voltando para o opção correta.

O último dos pressupostos, sobre ícones polissêmicos $(d)$, apesar do alto índice de acertos, não pôde ser confirmado, uma vez que se percebeu
Realização:

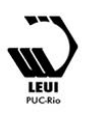




\section{$16^{\circ}$ \\ ERGODESIGN USIHC CINAHPA}

nas observações que alguns participantes pareciam confusos ao ver o mesmo ícone em vários lugares relacionados com categorias diferentes. Apesar de alguns participantes reconhecerem, por exemplo, que o carrinho de compras era um ícone que já conheciam (pressuposto $b$ ), ficavam em dúvida se clicavam no topo ou em loja virtual, que eram categorias diferentes que tinham em comum o ícone do carrinho.

\section{Conclusão}

Este artigo relatou a avaliação de usabilidade a partir da aplicação de um teste empírico com usuários, cujo objetivo era estudar formas de representações gráficas de ícones para auxiliar na navegação de surdos em websites. Foi visto que, por não possuírem o feedback auditivo, os surdos apresentam dificuldades de leitura e compreensão de textos da língua oral. A imagem, no entanto, possui um papel fundamental no processo de aprendizagem, devido a sua capacidade de percepção visual aguçada. Com base nisso, foi construído um website com ícones a partir de quatro pressupostos. O primeiro deles, ia ao encontro da teoria de Primeiridade proposta por Peirce (2005), ou seja, de que ícones que possuem a forma semelhante de objetos são facilmente reconhecíveis, inclusive pelos surdos, uma vez que esses ícones mantém as qualidades da forma dos objetos. De fato, esse pressuposto foi confirmado, tendo em vista que os participantes não demonstraram dificuldades em reconhecer os ícones icônicos e, na maior parte das tarefas, conseguiram navegar e encontrar as respostas corretas. O segundo pressuposto, por sua vez, ressaltava a importância da convencionalização dos ícones, já que eles poderiam ser reconhecidos mesmo que se tratassem de metáforas não partilhadas entre surdos e ouvintes. Esse pressuposto também se confirmou pelas observações e desempenho nas tarefas realizadas. Como os surdos pesquisados já eram experientes na navegação em websites, não foi difícil para eles reconhecerem o símbolo da casa como representante da página inicial. O terceiro pressuposto, que tratava das categorias abstratas, difíceis de representar, propunha a reprodução dos ícones a partir do desenho das características em $16^{\circ}$ Ergodesign - Congresso Internacional de Ergonomia e Usabilidade de Interfaces Humano Tecnológica: Produto, Informações Ambientes Construídos e Transporte

$16^{\circ}$ USIHC - Congresso Internacional de Ergonomia e Usabilidade de Interfaces Humano Computador

CINAHPA | 2017 - Congresso Internacional de Ambientes Hipermídia para Aprendizagem. comum ou do agrupamento de características diferentes dos subitens. Mais uma vez, esse pressuposto pôde ser confirmado com base nas repostas e no desenvolvimento das tarefas. Por fim, o quarto pressuposto previa que determinados ícones poderiam aparecer várias vezes na interface, associados a categorias imediatas, o que não se confirmou, uma vez que quando viam o mesmo ícone com elementos diferentes e em locais diferentes o nível de incertezas aumentava, fazendo com que clicassem em ambos os ícones em busca da opção correta.

Esses resultados poderão ser utilizados para a construção de websites mais acessíveis para surdos. Espera-se com eles poder melhorar o desempenho de surdos em tarefas de navegação na internet e com isso, facilitar o seu acesso ao conhecimento. Contudo, pretende-se entrelaçar esses dados obtidos com entrevistas semiestruturadas, fruto de novas publicações, a fim de alcançar um leque maior de informações sobre as formas de representações gráficas apropriadas para o público surdo.

\section{BIBLIOGRAFIA}

FAJARDO, I.; ABASCAL, J.; CAÑAS, J. J. The role of working memory and long term memory in deaf users' hypertext navigation: review of guidelines for web accessibility. In: STARY, C.; STEPHANIDIS, C. User-Centered Interaction Paradigms for Universal Access in the Information Society. 8th ERCIM Workshop on User Interfaces for All. Viena, 2004, v. 3196, p. 320-325.

FLOR, C. S. Recomendações para a criação de pistas proximais de navegação em websites voltadas para surdos pré-linguísticos. 2016. $336 \mathrm{p}$. Tese (Doutorado em Engenharia e Gestão do Conhecimento) - Programa de Pós-graduação em Engenharia e Gestão do Conhecimento, Universidade Federal de Santa Catarina, Florianópolis, 2016.

FREEPIK. Flaticon: free vector icons. Disponível em: <http://www.flaticon.com/>. Acesso em: 10 mar. 2015.
Realização:

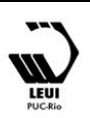




\section{$16^{\circ}$ \\ ERGODESIGN USIHC CINAHPA}

$16^{\circ}$ Ergodesign - Congresso Internacional de Ergonomia e Usabilidade de Interfaces Humano Tecnológica: Produto, Informações Ambientes Construídos e Transporte

$16^{\circ}$ USIHC - Congresso Internacional de Ergonomia e Usabilidade de Interfaces Humano Computador

CINAHPA | 2017 - Congresso Internacional de Ambientes Hipermídia para Aprendizagem.

HICKS, J. The icon handbook. United Kingdom: Five Simple Steps, 2011. 304 p.

NIELSEN, J. Usability 101: introduction to usability. 2012. Disponível em: $<$ http://www.nngroup.com/articles/usability-101introduction-to-usability/>. Acesso em: 17 out. 2014.

PERASSI, R. Semiótica: texto didático. Florianópolis: UFSC. [2009?]. 48 p.

PEIRCE, C. S. Semiótica. Tradução de José Teixeira Coelho Neto. 3. ed. São Paulo: Perspectiva, 2005. 337 p.

QUEVEDO, S. R. P. Narrativas hipermidiáticas para ambiente virtual de aprendizagem inclusivo. 2013. $379 \mathrm{f}$. Tese (Doutorado em Engenharia e Gestão do Conhecimento) - Programa de Pósgraduação em Engenharia e Gestão do Conhecimento, Universidade Federal de Santa Catarina, Florianópolis, 2013.

REITSMA, P. Computer-based exercises for learning to read and spell by deaf children. Journal of Deaf Studies and Deaf Education, Oxford, p. 1-12, 2008.

SÁ, T. H. M. O estilo gráfico flat design na gestão da interface visual nos dispositivos móveis. 2014. 91 f. Dissertação (Mestrado em Design) Universidade Federal de Santa Catarina, Florianópolis, 2014.

SANTAELLA, L.; NÖTH, W. Imagem: cognição, semiótica, mídia. São Paulo: Iluminuras. 2009. $224 \mathrm{p}$.

\section{Agradecimentos}

Aos programas Capes-Aux-PE Proesp/2009 e MCTI/CNPQ/Universal 14/2014 